\title{
The Effects of High-Dose and Low-Dose Tryptophan Depletion on Mood and Cognitive Functions of Remitted Depressed Patients.
}

Citation for published version (APA):

Booij, L., van der Does, A. J. W., Haffmans, P. M. J., Riedel, W. J., Fekkes, D., \& Blom, M. J. B. (2005). The Effects of High-Dose and Low-Dose Tryptophan Depletion on Mood and Cognitive Functions of Remitted Depressed Patients. Journal of Psychopharmacology, 19(3), 267-275. https://doi.org/10.1177/0269881105051538

Document status and date:

Published: 01/01/2005

DOI:

10.1177/0269881105051538

Document Version:

Publisher's PDF, also known as Version of record

\section{Document license:}

Taverne

Please check the document version of this publication:

- A submitted manuscript is the version of the article upon submission and before peer-review. There can be important differences between the submitted version and the official published version of record.

People interested in the research are advised to contact the author for the final version of the publication, or visit the DOI to the publisher's website.

- The final author version and the galley proof are versions of the publication after peer review.

- The final published version features the final layout of the paper including the volume, issue and page numbers.

Link to publication

\footnotetext{
General rights rights.

- You may freely distribute the URL identifying the publication in the public portal. please follow below link for the End User Agreement:

www.umlib.nl/taverne-license

Take down policy

If you believe that this document breaches copyright please contact us at:

repository@maastrichtuniversity.nl

providing details and we will investigate your claim.
}

Copyright and moral rights for the publications made accessible in the public portal are retained by the authors and/or other copyright owners and it is a condition of accessing publications that users recognise and abide by the legal requirements associated with these

- Users may download and print one copy of any publication from the public portal for the purpose of private study or research.

- You may not further distribute the material or use it for any profit-making activity or commercial gain

If the publication is distributed under the terms of Article $25 \mathrm{fa}$ of the Dutch Copyright Act, indicated by the "Taverne" license above, 

low-dose tryptophan depletion on mood and cognitive functions of remitted depressed patients

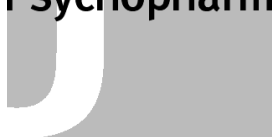

Journal of Psychopharmacology 19(3) (2005) 267-275 (C) 2005 British Association for Psychopharmacology ISSN 0269-8811 SAGE Publications Ltd, London, Thousand Oaks, CA and New Delhi $10.1177 / 0269881105051538$

Linda Booij Department of Psychology, Leiden University, Leiden, The Netherlands and Psychomedical Center Parnassia, The Hague, The Netherlands.

A. J. Willem Van der Does Department of Psychology, Leiden University and Department of Psychiatry, Leiden University Medical Center, Leiden, The Netherlands.

P. M. Judith Haffmans Psychomedical Center Parnassia, The Hague, The Netherlands.

Wim J. Riedel Department of Psychiatry, University of Cambridge, Cambridge, UK, Faculty of Psychology, Maastricht University, Maastricht, The Netherlands and GlaxoSmithKline, Translational Medicine and Technology, Cambridge, UK.

Durk Fekkes Departments of Psychiatry and Neuroscience, Erasmus University Medical Center, Rotterdam, The Netherlands.

Marc J. B. Blom Psychomedical Center Parnassia, The Hague, The Netherlands.

\begin{abstract}
It has frequently been demonstrated that acute tryptophan depletion (ATD) induces a transient depressed mood in some patients who are in remission from depression. However, the effects of ATD on cognitive processes in remitted depressed patients have not been investigated. The aim of the present study was to investigate the effects of different extents of depletion on mood and cognitive tasks involving neutral and emotional stimuli. Twenty patients in remission or in partial remission from depression received ATD in a double-blind, crossover design. Mood was assessed at both sessions before, at $+6.5 \mathrm{~h}$ and $+24 \mathrm{~h}$ after

depletion. Cognitive assessment in both sessions started at $+4.75 \mathrm{~h}$, and also before and after the whole procedure. The ATD mixtures induced the expected reductions of plasma tryptophan levels. High-dose ATD induced a depressive response in a subsample of patients and impaired the
\end{abstract}

processing of positive information independent of mood change. Attention for neutral stimuli (Stroop interference) improved in a dosedependent manner. ATD may affect mood and cognition via different pathways: one implicated in mood regulation and the processing of emotional information, and one for the processing of neutral information. The first pathway may be more important for discriminating vulnerability to impaired serotonin function. The comparison of the effects of high-dose and low-dose ATD is useful for those studies aiming to investigate the relationships among $5-\mathrm{HT}$, mood and cognition.

\section{Keywords}

catecholamine, cognition, depletion, depression, serotonin, tryptophan

\section{Introduction}

Depression impairs cognitive processes, including memory, attention, executive function and motor function (Austin et al., 2001). Although serotonin (5-hydroxytryptamine; 5-HT) neurotransmission plays an important role in the pathophysiology of depression (Maes and Meltzer, 1995), the relationship of 5-HT, depressed mood and cognitive processes remains poorly understood. In the acute tryptophan depletion (ATD) paradigm, 5-HT function is temporarily lowered by restricting the availability of its precursor
L-Tryptophan (Trp) (Young et al., 1985). It has frequently been demonstrated that ATD temporarily induces a return of depressive symptoms in a subset of selective serotonin reuptake inhibitor (SSRI) treated remitted depressed patients (Delgado et al., 1990, 1999; Van der Does, 2001a; Booij et al., 2002, 2003). However, the effects of ATD on cognitive processes in these patients have not been studied.

In healthy samples, ATD had a selective negative effect on memory consolidation for verbal and non-verbal material (Park et al., 1994; Riedel et al., 1999; Schmitt et al., 2000; Sobczak et al.,

Corresponding author: Dr A. J. W. Van der Does, Department of Psychology, Leiden University, Wassenaarseweg 52, 2333 AK Leiden, The Netherlands. Email: vanderdoes@fsw.leidenuniv.nl 
2002; Harrison et al., 2004), and a positive effect on focused attention as indicated by reduced Stroop interference or by improved dichotic listening performance (Park et al., 1994; Schmitt et al., 2000).

Of particular interest are ATD studies investigating the effects on emotional material because a mood-congruent bias has often been demonstrated in depression. For example, depressed patients are more likely to learn and retrieve negative than positive information (Burt et al.1995). Research with the Emotional Stroop test has shown that depression-related words cause more interference than neutral or positive words (Gotlib, 1984; Segal et al., 1995). Consistent with this, ATD in healthy volunteers impaired the processing of positive information (Murphy et al., 2002) and decreased the recognition of fearful faces (Harmer et al., 2003b) but left mood unaffected. The results of these studies suggest that cognitive tests may be more sensitive measures of ATD-induced depression than mood scales.

However, the absence of depressive response in healthy samples limits the use of these samples in investigating the associations among 5-HT, depressive symptoms and cognitive function. If cognitive changes are more sensitive markers for changes in 5-HT function than symptom, changes in cognitive function following ATD may occur in patients without a depressive response. Second, cognitive changes may already occur after moderate depletion, with no effect on symptoms.

It has been suggested that failures to replicate the mood effects of ATD may have been due to insufficient depletion (Spillmann et al., 2001; Van der Does, 2001b). Therefore, although all previous studies have used a placebo-controlled design, it has been recommended to compare the effects of two different dosages of ATD (100 g versus $25 \mathrm{~g}$ amino acids), aimed at reducing plasma Trp levels by $80-90 \%$ and $40-50 \%$, respectively (Van der Does, 2001a).

The aim of the present study was to investigate the effects of moderate and strong reductions of Trp levels on mood and on cognitive tasks involving neutral and affective stimuli, in remitted depressed patients. The tested hypotheses were: (i) strong reductions of Trp levels, and not moderate reductions, will lead to a transient return of depressive symptoms and (ii) both moderate and strong reductions of Trp will lead to cognitive changes in patients with and without an ATD induced depressive response.

\section{Materials and methods}

\section{Participants}

Eligible patients were selected outpatients of a mood disorders clinic. Inclusion criteria were: age between 18 and 65 years; ongoing treatment with an SSRI or a serotonin noradrenaline reuptake inhibitor for at least 4 weeks, meeting DSM-IV criteria for depression in remission or partial remission, Hamilton Depression rating Scale (HRSD, 17-items) (Hamilton, 1960) lower than 15 (Frank et al., 1991). Exclusion criteria were: substance abuse within last 3 months, psychosis (lifetime), major physical illness, lactation, pregnancy. Diagnoses, demographic and clinical background variables were verified with the Structured Clinical Interview for DSM-IV (SCID-I) (First et al., 1995).

\section{Amino acids}

At each depletion session, patients received in randomized order either a high-dose (100 g) or a low-dose $(25 \mathrm{~g})$ ATD mixture. The composition of the 100-g mixture (aimed at reducing Trp levels by $90 \%$ ) was similar to that reported by Delgado et al., 1990). The 25-g mixture consisted of the same amino acids (AAs) but at one quarter of the amount (Krahn et al., 1996). All AAs were mixed with cold water $\left(4^{\circ} \mathrm{C}\right)$ to a final volume of $300 \mathrm{ml}$. Liquid chocolate syrup was added and the mixture was served chilled to limit the unpleasant taste of some AAs. Patients were kept on a 24-h low-Trp diet (160 mg/day) before both sessions. The meals had an energy value of $2300 \mathrm{kCal}$ and were prepared by dieticians. During the ATD sessions, water (de)caffeinated coffee, (herbal) tea, orange juice and protein-poor $(<0.05 \mathrm{~g})$ cookies were allowed in standard amounts. Caffeinated coffee or tea was not allowed to be consumed for approximately $1 \mathrm{~h}$ before the cognitive tasks. The experimenter took care that the amount of caffeine consumed was not larger than usual. Patients had a low-Trp lunch $3 \mathrm{~h}$ after drinking the mixture (Riedel et al., 1999; Schmitt et al., 2000; Sobczak et al., 2002)

\section{Instruments}

Mood Symptoms were assessed with the 10-item MontgomeryAsberg Depression Rating Scale (MADRS) (Montgomery and Asberg, 1979). Sleep items were omitted. The 17-item HRSD was also administered. Because the results were very similar, only the MADRS will be reported.

Cognition The cognitive tests took approximately $60 \mathrm{~min}$. Parallel versions were used, except for the Stroop tasks and the Left/Right task.

\section{Stroop Word Colour test}

The Stroop test measures focused attention and response inhibition. Names of colors (red, yellow, blue and green) printed in black were presented one by one for a maximum of $1500 \mathrm{~ms}$ on a computer screen. Participants were instructed to read these words as fast as possible (Condition I). Next, colored patches were presented (Condition II). Finally, the names of colors printed in an incongruent colour were presented and participants were instructed to name the colour of the ink (Condition III). Median reaction times (RTs) and errors were recorded. Interference was defined as the extra time needed for condition III relative to the average of conditions I and II.

\section{Emotional Stroop test}

An Emotional Stroop test was used to assess attentional bias for emotional material. The stimuli were positive, neutral or depressionrelated words. Words printed in colour were presented consecutively on a computer screen. Participants were asked to name the colors as quickly as possible. The order of the word categories was randomized over the patients but fixed for each patient during all sessions. The order of the words within each category was randomized in all sessions. 


\section{Left/Right Choice RT}

This task was used to assess motor speed and response inhibition as a function of task difficulty. The word 'left' or 'right' was presented in randomized order either at the left or the right side of the screen. Participants were instructed to respond to the meaning of the word but to ignore its location, as fast as possible. The task consisted of two consecutive subtasks in which the stimulus interval differed (1000 ms fixed versus $500-1500 \mathrm{~ms}$ variable). Correct responses and RTs were registered.

\section{Tower of London (TOL)}

The TOL (Owen et al., 1995) is a planning task consisting of three colored balls (red, yellow and blue) placed on three sticks in various arrangements. Two arrangements were presented on the upper and lower half of the screen. The patient was instructed to indicate the minimal number of moves necessary to change the first arrangement into the second (two to six moves). Correct responses and RTs were registered.

\section{Letter Fluency}

This test measures strategy-driven retrieval from semantic memory within a fixed time span. Participants were instructed to produce as many correct four-letter words with the same initial letter as possible within $1 \mathrm{~min}$. Starting letters were H, M, R and L. The numbers of correct, nonsense and double-reported words were registered.

\section{Abstract Patterns Recognition task (APRT)}

The APRT (Rubinsztein et al., 2001) measures (speed of) retrieval of non-verbal abstract information from short- and long-term memory. Sixteen abstract patterns were presented consecutively for $3000 \mathrm{~ms}$, with $500 \mathrm{~ms}$ intervals. Participants were instructed to memorize the patterns. After three presentations of the complete series, two patterns were presented simultaneously; one that had been learned and a new pattern. Participants had to indicate as fast as possible which one had been previously presented. The recognition procedure was repeated after 35 min, during which verbal tasks were administered.

\section{Blood plasma}

Venous blood was obtained $(10 \mathrm{ml})$ using ethylenediaminetetraacetic acid tubes to determine total plasma Trp and the other large neutral amino acids (LNAA) phenylalanine, tyrosine, isoleucine, leucine and valine. Immediately after sampling, the blood was centrifuged for $20 \mathrm{~min}$ at $2650 \mathrm{~g}$ (maximum) and the plasma was stored at $-65^{\circ} \mathrm{C}$. Quantitative amino acid analysis was performed by high-performance liquid chromatography (HPLC) as described previously (Fekkes et al., 1995). The concentrations 5-hydroxyindoleacetic acid (5-HIAA) and homovanillic acid (HVA) were measured in plasma by HPLC employing electrochemical detection (detection limit in plasma, $1 \mathrm{nM}$ ). Quantification was performed by measuring peak heights, and absolute concentrations were calculated using a combined external and internal standard (applying $\alpha$-methyl 5-HT) method (Fekkes et al., 1997).

\section{Procedure}

After providing their written informed consent, participants were invited to a screening interview that included the SCID-I, HRSD, MADRS and an interview with a dietician. The cognitive tasks were also administered. The time between the intake and the first ATD session was approximately 1 week. During day 1 of each session, patients consumed the prepacked low-Trp meal. Patients came to the laboratory at $08.00 \mathrm{~h}$ or $09.00 \mathrm{~h}$ of day 2 , after an overnight fast. Mood ratings and a blood sample were obtained $(-1 \mathrm{~h})$, followed by the ATD drink $(0 \mathrm{~h})$. For the next $4.5 \mathrm{~h}$, patients remained in a private research room. Neutral videos and magazines were available. They completed the cognitive tasks at $+4.75 \mathrm{~h}$. A blood sample was taken at $+6 \mathrm{~h}$ and mood was assessed at $+6.5 \mathrm{~h}$. Before participants went home, they received a sandwich or a Trpenriched snack and were instructed to resume their regular meals. Mood ratings and a blood sample were taken the next morning. This procedure was repeated at least 4 days later; those who had received high-dose ATD received low-dose ATD and vice versa. The day after the second session, participants also completed the cognitive test battery (after the mood assessment). All patients were tested individually and were paid $€ 115$ for their participation.

\section{Design}

The study was conducted according to a randomized, double-blind, crossover design with two sessions, separated by at least 4 days. The hospital pharmacist took care of the randomization. To compare the effects of both low- and high-dose ATD with baseline levels, cognitive performance after ATD was compared with the mean of the first and the fourth administration of the neuropsychological tests.

\section{Statistical analysis}

Before analysis, all variables were examined for accuracy of dataentry, missing values and fit between their distributions and the assumptions of the statistical analyses. Clinical and demographic variables were investigated by means of chi-square tests and univariate General Linear Models (GLM). Differences in mood and cognitive performance between patients and controls were analysed by multivariate GLM.

The effects of the different doses of ATD on the outcome variables were analysed by GLM for repeated measures. For the MADRS, intervention (low-dose versus high-dose) and time ( $-1 \mathrm{~h}$, $+6.5 \mathrm{~h}$ and $+24 \mathrm{~h}$ ) were the within subjects factors. Intervention (baseline versus low-dose versus high-dose ATD) was used as within-subject factor for the cognitive measures. 'Baseline intervention' measures were defined as the average score obtained during the intake and post-intervention sessions. Contrast tests were used to investigate differences between specific interventions. $p$-values for contrast tests were corrected for multiple comparisons by dividing the $p$-value of 0.05 by the number of intervention 
comparisons (baseline versus low-dose; baseline versus high-dose; low-dose versus high-dose), implicating that differences between interventions were tested at the $0.05 / 3=0.02$ level of significance. To further investigate the relationship between depressive symptoms, cognitive function and 5-HT, post-hoc analyses were conducted by adding ATD depressive response ('responder' versus 'non-responder') as a between subjects variable, based on a clear division in magnitude of symptom change between the groups (see below). Second, the influences of minor mood changes were investigated by separate analyses entering delta MADRS scores $[t+6.5 \mathrm{~h}-t(-1 \mathrm{~h})$ following high-dose ATD $]$ as a covariate.

There was no need to correct the $p$-value for the effects of ATD on depressive symptoms because these comparisons were planned, based on previous ATD studies in remitted depressed patients (Booij et al., 2002, 2003).

\section{Results}

Twenty-three participants entered the study (13 males, 10 females). Two patients (both males) dropped out after the first session; the first case due to a severe headache on the depletion day (after lowdose ATD) and the second case because of health problems after the first session (high-dose ATD) unlikely to be caused by ATD. These patients were not included in the analyses. The ATD mixtures were well tolerated; one female patient vomited approximately 10 min after ingestion of high-dose ATD, but she was able to complete both sessions. Because the reduction of plasma Trp levels in the high-dose condition was only marginally higher than in the low-dose condition in this participant (64\% versus 55\%) and much lower than the average reduction in the high-dose condition (see below), this patient was excluded from the analyses.

The clinical and demographic characteristics of the remaining, 20 patients are presented in Table 1 . Two patients had very recently tapered off antidepressant medication. These patients were retained because unmedicated remitted depressed patients are also likely to respond to ATD (Smith et al., 1997; Booij et al., 2002).

\section{Data screening}

RTs of the TOL and the APRT were $\log _{10}$-transformed because of a non-normal distribution. Using Mahalonobis distances and standardized residuals criterion, one statistical outlier was detected on the MADRS $\left(D^{2}=16.2 ; z=3.2\right)$. This patient responded in the low-dose ATD condition and not after high-dose ATD. Another patient had an extreme increase in neutral Stroop interference levels after high-dose ATD $\left(D^{2}=14.7 ; z=3.05\right)$, and was a statistical outlier. One patient experienced a strong emotional reaction during the emotional Stroop task and interrupted the task. Another patient missed all 3- and 4-step problems of the TOL at intake and after the low-dose ATD session. Blood samples were missing for one patient at the post intervention day after both sessions. Analyses were conducted with and without statistical outliers. Cases with missing data were omitted separately by analysis.
Table 1 Clinical and demographic characteristics of the patient sample $(n=20)$

\begin{tabular}{ll}
\hline Characteristic & \multicolumn{1}{c}{ Value } \\
\hline M/F & $11 / 9$ \\
Age \pm SD & $48.7 \pm 7.9$ \\
Education level & $n=9$ \\
$\quad$ High & $n=7$ \\
Medium & $n=3$ \\
Low & $n=13$ (two SSRI treatment \\
Type of medication & free for 1 month) \\
SSRI & $n=7$ (75-225 mg) \\
& \\
SNRI & $n=3$ \\
Diagnosis & $n=11$ \\
$\quad$ Subtype of last depressive episode: & $n=6$ \\
$\quad$ Not melancholic, atypic or catonic & $n=2$ \\
Melancholic & $4.8 \pm 4.4$ (range 1-16) \\
Atypic & $4 / 16$ \\
Seasonal pattern & $n=13$ \\
Mean \pm SD past episodes & $n=7$ \\
Single/recurrent & $5.9 \pm 5.6$ (range 1-24) \\
Partial remission &
\end{tabular}

SSRI, Selective serotonin reuptake inhibitor; SNRI, serotonin noradrenaline reuptake inhibitor.

\section{Biochemical effects}

Both ATD mixtures significantly reduced total Trp and the Trp/ LNAA ratio. Total Trp was significantly more reduced after a high than after low-dose ATD (mean \pm SE change: $-86.3 \pm 1.2 \%$ versus $-46.8 \pm 3.2 \%)$. A similar pattern was observed for Trp/LNAA ratio $(-93.3 \pm 0.9 \%$ versus $-42.2 \pm 3.8 \%)$. The variance of reductions was small; for each patient, the reduction was approximately twice as large after a high-dose than after a low-dose.

Post-hoc analyses were conducted to investigate the effects of ATD on tyrosine levels. Unexpectedly, tyrosine levels and tyrosine/ LNAA ratio increased significantly after a high-dose ATD (mean \pm SE change: $+214.0 \pm 25.3 \%$ and $+56.4 \pm 14.5 \%)$, but not after a low-dose ATD $(-2.0 \pm 3.8 \%$ and $+11.2 \pm 3.6 \%)$. To further investigate the influence on dopamine (DA) and 5-HT function, HVA and 5-HIAA levels were measured post-hoc in the first 10 patients. At $t(+6.5 \mathrm{~h})$, high-dose ATD significantly decreased 5-HIAA levels compared to $t(-1 \mathrm{~h})(-50.3 \%)[F(1,9)=108.85, p<0.001]$. There was no significant change of HVA levels $(-23.6 \%)[F(1,9)=0.76$, not significant]. After omitting one patient who had extremely high HVA levels before depletion, the change in HVA levels was $+3.3 \%$.

\section{Symptoms}

The increase of MADRS scores at $t(+6.5 \mathrm{~h})$ was significantly higher after high-dose ATD than after low-dose ATD, as shown by a 
Table 2 Effects of acute tryptophan depletion (ATD) on the biochemical outcome measures and mood (mean \pm SE)

\begin{tabular}{|c|c|c|c|c|c|c|}
\hline & \multicolumn{3}{|c|}{ Low-dose ATD } & \multicolumn{3}{|l|}{ High-dose ATD } \\
\hline & Pre & Post & $+24 h$ & Pre & Post & $+24 h$ \\
\hline Total TRP & $38.4 \pm 1.5$ & $20.4 \pm 1.6$ & $38.0 \pm 1.6$ & $39.4 \pm 1.3$ & $5.3 \pm 0.5$ & $35.6 \pm 1.8$ \\
\hline TRP/LNAA & $8.7 \pm 0.3$ & $4.9 \pm 0.3$ & $7.2 \pm 0.3$ & $9.1 \pm 0.3$ & $0.6 \pm 0.1$ & $6.3 \pm 0.3$ \\
\hline 5-HIAA & & & & $28.2 \pm 1.9$ & $14.1 \pm 1.1$ & \\
\hline Tyrosine & $57.3 \pm 2.9$ & $56.2 \pm 3.5$ & $62.2 \pm 4.9$ & $58.0 \pm 3.5$ & $173.4 \pm 11.5$ & $67.0 \pm 6.3$ \\
\hline Tyrosine/LNAA & $13.4 \pm 0.5$ & $14.9 \pm 0.8$ & $11.9 \pm 0.6$ & $13.6 \pm 0.6$ & $20.6 \pm 1.4$ & $11.9 \pm 0.5$ \\
\hline HVA & & & & $85.2 \pm 25.9$ & $65.1 \pm 10.7$ & \\
\hline MADRS & $3.7 \pm 0.9$ & $3.7 \pm 0.9$ & $3.6 \pm 0.9$ & $4.6 \pm 0.9$ & $7.9 \pm 1.8$ & $3.4 \pm 1.0$ \\
\hline
\end{tabular}

TRP, L-Tryptophan; LNAA, large neutral amino acids; 5-HIAA, 5-hydroxyindoleacetic acid; HVA, homovanillic acid; MADRS, Montgomery-Asberg Depression Rating Scale.

Table 3 Mean \pm SE of the cognitive tasks, broken down by intervention

\begin{tabular}{|c|c|c|c|c|}
\hline Task & Baseline $^{a}$ & Low-dose ATD & High-dose ATD & Intervention effect \\
\hline \multicolumn{5}{|l|}{ SCWT } \\
\hline Condition I (ms) & $498.5 \pm 12.4$ & $519.2 \pm 10.6^{b}$ & $534.8 \pm 11.6^{b}$ & $F(2,38)=5.52, p=0.01$ \\
\hline Condition II (ms) & $558.5 \pm 16.9$ & $550.6 \pm 13.3$ & $577.9 \pm 16.4$ & $F(2,38)=2.13, p=0.13$ \\
\hline Condition III (ms) & $789.2 \pm 25.0$ & $759.8 \pm 22.0$ & $762.7 \pm 24.1$ & $F(2,38)=1.80, p=0.18$ \\
\hline Interference $(\%)$ & $48.3 \pm 3.3$ & $42.4 \pm 3.4^{c}$ & $34.7 \pm 2.9^{b}$ & $F(2,36)=9.85, p<0.001$ \\
\hline \multicolumn{5}{|l|}{ Emotional Stroop } \\
\hline Positive words (ms) & $707.1 \pm 18.0$ & $709.8 \pm 19.9$ & $717.2 \pm 20.0$ & $F(2,36)=0.22, p=0.80$ \\
\hline Negative words (ms) & $737.3 \pm 21.2$ & $724.0 \pm 23.9$ & $708.1 \pm 21.6$ & $F(2,36)=1.47, p=0.24$ \\
\hline Neutral words (ms) & $711.4 \pm 16.2$ & $706.6 \pm 22.8$ & $681.7 \pm 18.1$ & $F(2,36)=1.51, p=0.23$ \\
\hline Positive Interference(\%) & $-0.5 \pm 1.3$ & $1.0 \pm 1.9$ & $5.3 \pm 1.7^{b}$ & $F(2,36)=5.09, p=0.01$ \\
\hline Negative Interference(\%) & $3.7 \pm 2.0$ & $2.7 \pm 2.0$ & $4.0 \pm 2.0$ & $F(2,36)=0.15, p=0.86$ \\
\hline \multicolumn{5}{|l|}{ Left/Right task } \\
\hline Congruent (ms) & $659.1 \pm 11.6$ & $665.7 \pm 16.2$ & $660.0 \pm 16.8$ & $F(2,38)=0.02, p=0.98$ \\
\hline Incongruent (ms) & $682.9 \pm 11.7$ & $678.3 \pm 18.6$ & $679.9 \pm 19.1$ & \\
\hline Congruent (variable) & $668.4 \pm 12.8$ & $664.3 \pm 15.3$ & $669.5 \pm 17.3$ & $F(2,38)=0.37, p=0.69$ \\
\hline Incongruent(variable) & $683.0 \pm 12.1$ & $689.0 \pm 11.3$ & $700.7 \pm 15.6$ & \\
\hline \multicolumn{5}{|l|}{ Word Fluency } \\
\hline No. correct $0-30 \mathrm{~s}$ & $7.5 \pm 0.6$ & $8.0 \pm 0.5$ & $9.0 \pm 0.6^{b}$ & $F(2,38)=4.29, p=0.02$ \\
\hline No. correct $0-60 \mathrm{~s}$ & $12.2 \pm 1.0$ & $13.0 \pm 1.1$ & $12.2 \pm 0.8$ & $F(2,38)=0.63, p=0.53$ \\
\hline \multicolumn{5}{|l|}{ Tower of London } \\
\hline \multicolumn{5}{|l|}{ Percent correct } \\
\hline 2-step & $87.1 \pm 2.7$ & $85.3 \pm 3.5$ & $84.2 \pm 3.7$ & No. correct: \\
\hline 3-step & $86.0 \pm 3.7$ & $85.8 \pm 3.7$ & $85.3 \pm 2.5$ & $F(2,36)=0.35, p=0.71$ \\
\hline 4-step & $79.5 \pm 3.7$ & $75.8 \pm 5.1$ & $80.5 \pm 3.3$ & \\
\hline 5-step & $61.8 \pm 4.9$ & $63.7 \pm 5.3$ & $67.9 \pm 5.9$ & \\
\hline \multicolumn{5}{|l|}{ Reaction time (ms) } \\
\hline 2-step & $5852 \pm 410$ & $6063 \pm 564$ & $5659 \pm 429$ & Median reaction time: \\
\hline 3-step & $7359 \pm 615$ & $6813 \pm 639$ & $7110 \pm 697$ & $F(2,36)=0.33, p=0.72$ \\
\hline 4-step & $10310 \pm 838$ & $9456 \pm 1133$ & $9951 \pm 954$ & \\
\hline 5-step & $15836 \pm 1549$ & $15894 \pm 2130$ & $15338 \pm 1742$ & \\
\hline \multicolumn{5}{|l|}{ APRT } \\
\hline Percent correct, STM & $80.5 \pm 2.2$ & $83.1 \pm 2.6$ & $78.4 \pm 2.8$ & $F(2,38)=1.37, p=0.26$ \\
\hline Percent correct, LTM & $77.3 \pm 2.5$ & $78.1 \pm 2.7$ & $73.7 \pm 3.8$ & $F(2,38)=1.15, p=0.33$ \\
\hline Reaction time, STM (ms) & $2159 \pm 131$ & $2068 \pm 92.4$ & $2195 \pm 171$ & $F(2,38)=0.57, p=0.57$ \\
\hline Reaction time, LTM (ms) & $2078 \pm 107$ & $1966 \pm 103$ & $1890 \pm 110$ & $F(2,38)=1.67, p=0.20$ \\
\hline
\end{tabular}

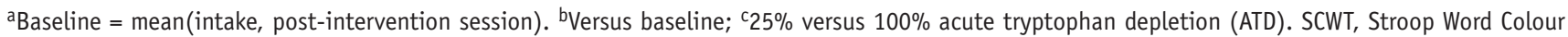
test; APRT, Abstract Patterns Recognition task; STM, short-term memory; LTM, long-term memory. 
significant interaction between time of rating and intervention $[F(2,36)=7.32, p=0.002]$ (Table 2). Contrast test between $t(+6.5 \mathrm{~h})$ and $t(-1 \mathrm{~h})$ in the high-dose condition was not significant when the statistical outlier was included $[F(1,19)=2.51, p=0.13]$ There were no baseline differences, nor was there any difference in mood between $t(-1 \mathrm{~h})$ and $t(+24 \mathrm{~h})$ in both conditions.

The MADRS change score data revealed two clearly separable groups: seven patients had a change of at least 6 points (range 6-12 points), and the remaining 13 patients had no change (range $-1,2$ points). This clear division allowed us to conduct post-hoc analyses of the mood effect on cognitive performance by comparing 'responders' and 'non-responders', defining responders as those who had at least a 6-point MADRS increase (see below).

\section{Cognition}

The mean \pm SE of all cognitive measures are presented in Table 3 .

Cognitive performance at intake and learning effects To investigate potential learning effects on the cognitive tasks in the patient group, performance for the intake and post-intervention sessions was compared by paired $t$-tests or non-parametric tests. Improved performance was observed at the post-intervention session on all outcome measures of the TOL, except for the number of correct responses of the 2- and 4-step problems. A small learning effect was also found for the Left/Right task, but only during the fixed interval condition in both the congruent ( 677 versus $659 \mathrm{~ms}$ ) and incongruent trials (691 versus $674 \mathrm{~ms}$ ). Patients became slower during condition I of the Stroop Test (492 versus $509 \mathrm{~ms}$ ). To investigate whether high-dose ATD could influence cognitive performance the next day, performances at intake and at the postintervention session of patients that received high-dose ATD in the second session were compared with those that received high-dose ATD in the first session by multivariate GLM, entering 'order of intervention' as a between subjects variable. Patients who received high-dose ATD in the second session were faster on Cards I and II of the Neutral Stroop task at intake [Card I: $F(1,18)=7.27, p=$ 0.01; Card II: $F(1,18)=9.90, p=0.01]$ and at the post-intervention session [Card I: $F(1,18)=9.74, p=0.01$; Card II: $F(1,18)=6.47$, $p=0.01]$, indicating that the effects could not be due to the ATD mixture.

The suitability of taking the mean of the intake and the postintervention sessions as a baseline measure was further checked by a repeated measures analyses, with 'session' (intake versus postintervention session) as a within subjects factor and 'order' (highversus low-dose ATD first) as a between subjects factor. There were no order-session interactions on any of the tests, indicating that the average score of these two sessions can be used reliably as a baseline score.

\section{Effects of ATD on cognitive performance}

Neutral Stroop task. Compared to baseline, ATD was associated with decreased interference levels in a dose-dependent manner. High-dose ATD significantly decreased interference levels compared to baseline $[F(1,18)=13.41, p=0.002]$ and low-dose
ATD $[(F(1,18)=13.58, p=0.002]$. Low-dose ATD also decreased interference levels, but the difference with baseline levels was a statistically significant trend $[(F(1,18)=3.50, p=0.08]$. An additional analysis including depressive response as a between subjects factor showed that responders were no more or less affected on the Stroop task than non-responders, neither were there any order effects. Inclusion of the statistical outlier revealed decreased interference levels in the low-dose condition $[F(1,19)=4.88, p=0.04]$ and in the high-dose condition $[F(1,19)=10.68, p=0.004]$ relative to baseline, with no difference between low-and high-dose $[F(1,19)=1.68, p=0.21]$.

Emotional Stroop Task. High- but not low-dose ATD significantly increased interference levels for positive words $[F(1,18)=15.84$, $p=0.001]$, which was independent of depressive response. ATD had no effect on interference levels for negative words. Post-hoc inclusion of the between-subjects factor 'responder versus nonresponder' revealed a main effect of that variable $[F(1,17)=8.91$, $p<0.01]$ with higher interference levels at baseline for the responders compared to the non-responders $(3.7 \pm 2.0 \%$ versus $-0.2 \pm$ $1.8 \%$ ), but the presence of mood was not related to the extent of cognitive change following ATD. There were no order effects.

Other cognitive outcome measures. There were no main effects of ATD or interaction effects with depressive response on the Left/ Right task or TOL. However, an additional analysis using gender as a between subjects factor showed that, relative to low-dose ATD, high-dose ATD improved performance in females but tended to impair performance in males $[F(2,34)=7.11, p=0.003]$. Changes relative to baseline were not significant.

On the Word Fluency, ATD had no effect on the number of words produced within $1 \mathrm{~min}$. However, a more detailed analysis showed that, within the first $30 \mathrm{~s}$, high-dose ATD significantly increased word production compared to the baseline and low-dose ATD. There were no effects of depressive response or ATD order. ATD had no effect on any of the outcome measures of the APRT.

Influence of minor mood changes on cognition. To investigate the influence of minor mood changes on ATD-induced cognitive performance, the GLM Repeated measures analyses on all cognitive outcome measures were rerun entering the symptom change during high-dose ATD session as a covariate, rather than using a categoric division of responders and non-responders. Overall, the results were very similar: when the responder $\times$ intervention interaction was significant (as described above), the significant results disappeared after $\triangle$ MADRS was entered as a covariate; when there was no responder $x$ intervention interaction, entering the covariate did not change the results.

Biochemical correlates. Changes in mood or cognitive performance during the high-dose ATD session did not correlate significantly with percentage change of tryptophan, 5-HIAA, tyrosine or HVA. A trend was found for percentage change of 5-HIAA levels and changes of neutral Stroop interference $(r=0.58, p=0.08)$. 


\section{Discussion}

The present study was successful in creating two ATD dosages, lowering plasma Trp levels by 40-50\% (25 g ATD; low-dose) and by $80-90 \%$ (100 g ATD; high-dose), as intended.

As expected, high-dose ATD produced a transient return of depressive symptoms in some participants, but not in all (Delgado et al., 1999; Spillmann et al., 2001). Low-dose ATD did not affect symptoms, despite a $46.8 \%$ reduction of Trp levels. The percentage of relapse after high-dose ATD (seven out of 20) is relatively low compared to Delgado et al. (1990) but similar to that reported in other studies in SSRI-treated remitted depressed patients (Bremner et al., 1997; O'Reardon et al., 2004). Patients in the study by Delgado et al. (1990) were clinically stable for approximately 4 weeks, whereas patients in the study by Bremner et al. (1997) and O'Reardon et al. (2004), as well as in the present study, had been in remission for approximately 6 months. As noted previously, differences in relapse rate may be related to the timing of the ATD procedure (Booij et al., 2002).

As hypothesized, cognitive changes occurred in patients with and without a depressive response, but the direction of change (improvement versus impairment) was dependent of the valence of stimuli used.

As in healthy volunteers, ATD improved focused attention for neutral stimuli (Park et al., 1994; Schmitt et al., 2000) and the changes in the present study were dose-dependent. Similarly, performance on working memory tasks (indicated by the TOL and fluency task) also improved slightly following ATD. Improved attentional performance following ATD may be due to the removal of 5-HT inhibiting actions on the DA system in the prefrontal cortex (Schmitt et al., 2000). High-dose ATD markedly increased tyrosine and the tyrosine/LNAA ratio, which are also involved in mood and cognition (Booij et al., 2003). This finding was unexpected because ATD effects on tyrosine levels have rarely been reported. However, a few other studies have reported rises in tyrosine levels (Carpenter et al., 1998; Klaassen et al., 1999). In healthy samples, tyrosine administration improved Stroop performance and working memory (Deijen et al., 1994), whereas acute phenylalanine tyrosine depletion (APTD) selectively impaired working memory performance (Harrison et al., 2004). However, low-dose ATD already tended to improve Stroop interference whereas catecholamine precursors remained largely unaffected. Furthermore, we found no relationship between changes in HVA or tyrosine and cognitive performance. Because tyrosine is also the precursor of noradrenaline, it is possible that improved attentional performance is partly related to enhanced noradrenaline function. It is recommended that the effects of ATD on levels of 3-methoxy-4-hydroxyphenylglycol (MHPG) are measured, in addition to studying APTD and ATD in the same patients.

By contrast to the effects of ATD on neutral material, high-dose ATD increased interference for positive words. Patients became somewhat faster in the neutral and negative word condition, but needed more time to process positive information. Impaired emotional processing was also observed in those individuals who showed no depressive response, which is in agreement with the results of an ATD study in healthy volunteers by Murphy et al. (2002), who found slower responses to happy but not sad words. Another study found that a single SSRI administration in healthy volunteers facilitated the recognition of facial expressions of happiness and fear (Harmer et al., 2003a).

Because we found no changes in symptoms following low-dose ATD, but some changes in cognitive functioning, these cognitive changes may be more sensitive markers of 5-HT function than symptoms. One possibility is that cognitive changes mediate the relationship between 5-HT and mood However, the findings are also consistent with the idea that cognitive and symptomatic changes occur independently.

The differential effects on attention that were found in the present study (improvement in the processing of neutral information versus impairment in the processing of positive information) may be brought about by different mechanisms. At least two pathways modulate the ATD-induced effects on mood and cognition: the orbital/ventral medial and dorsolateral regions (Bremner et al., 1997; Smith et al., 1999). The effects of ATD in the ventral neural system may be different in vulnerable and non-vulnerable populations. Using positron emission tomography, a recent study identified different pathways for two emotional processing systems: 'hot' emotional processing (schematical processing; the actual emotional response) and 'cold' emotional processing (propositional processing; the analytical, rational mode) (Schaefer et al., 2003). The first was associated with increased activation of the ventromedial and the latter with activation of the anterolateral prefrontal cortex (Schaefer et al., 2003). The ventral system may be more closely implicated in 5-HT vulnerability to depression than the dorsolateral system. Imaging studies are needed to test this hypothesis further.

\section{Methodological considerations}

An important issue in neuropsychopharmacological studies concerns choosing the optimal design. In the present study, we compared the effects of two interventions with the mean performance during the first and fourth administration of the neuropsychological tests. This is a variant of the conventional pretest-post-test control group design (Neale and Liebert, 1986) but, in this case, the group variable refers only to treatment order. Unlike studies that did not measure of baseline performance during the intervention sessions (Park et al., 1994; Gallagher et al., 2003), learning effects were minimal or absent. A disadvantage of the present design is that expectancy effects during the 'baseline' sessions may be different from the effects during the depletion sessions. However, differences in cognitive performance between the intake session and the post-intervention session were minimal and, if any, these were observed on different tasks and/or in the opposite direction to those observed at the time that Trp levels were minimized. Moreover, there were no differences between those who received low- or high-dose ATD first. Furthermore, depletion improved performance on neutral tasks. If the test procedure influences cognitive performance negatively (because of expectancy, fatigue, etc.), baseline cognitive performance would have been overestimated, 
resulting in smaller differences with the depletion sessions. In other words, the observed effects might have been bigger if a placebo condition had been concluded. Furthermore, a true placebo condition does not exist. Most ATD studies have used a control mixture containing 2.3-5.0 g Trp. This procedure causes a huge rise of Trp levels, varying from $10 \%$ to $500 \%$ (Weltzin et al., 1994; Klaassen et al., 1999). However, moderate increments (+45\%) of Trp or Trp/LNAA ratio have been shown to affect cognitive performance and symptoms (Markus et al., 1998; Schruers et al., 2000; Markus et al., 2002). Studies making a direct comparison between cognitive performance and symptoms after a Trp-free and Trp-containing mixture may overestimate the difference in effect. Regarding the depressive response, the commonly used placebo procedures have only very rarely resulted in small symptom increases (Van der Does, 2001a), making it unlikely that the present study produced false positive results.

A limitation is that we did not include a control group that received ATD, which did not allow us to investigate the interaction between a history of depression and ATD. Thus, we do not know whether the effects we are looking at are due to ATD itself at different doses, or some interaction between ATD, diagnosis and treatment. On the other hand, most neuropsychological tasks used in the present study have also been used in ATD studies in healthy samples (Schmitt et al., 2000; Rubinsztein et al., 2001; Sobczak et al., 2002), allowing us to make indirect comparisons.

It could be argued that allowing caffeine consumption during the ATD sessions until $1 \mathrm{~h}$ before the cognitive tasks comprises a confounding factor because caffeine consumption could influence mood, cognition and catecholamine turnover (Nehlig, 1999; Smith, 2002). On the other hand, caffeine withdrawal probably also influences behaviour during the depletion sessions because withdrawal symptoms such as negative mood, anxiety and cognitive performance generally begin within $12-24 \mathrm{~h}$, and are highest at $20-48 \mathrm{~h}$ after cessation (Nehlig, 1999), even in individuals with relatively low or moderate habitual caffeine consumption (Silverman et al., 1992; Nehlig, 1999; Smith, 2002). In the present study, cognitive performance during two active sessions was compared with the mean of two baseline, no depletion sessions, sessions in which it was not possible to keep rigid control on caffeine consumption for some hours before administration of the cognitive tasks. In addition, differences on mood, cognition and biochemical measures between the high- and low-dose ATD sessions were significant despite similar caffeine restrictions. Furthermore, if caffeine consumption affect symptoms, it probably occurs after excessive consumption and with the largest effect on anxiety levels (Smith, 2002), which remained unaffected. Hence, it is not very likely that the present effects are confounded by caffeine consumption.

To summarize, the present study has demonstrated that strong reductions induce cognitive changes in patients with and without a depressive response to ATD. Moderate reductions of Trp levels already induce slight cognitive changes, but not a depressive 'relapse'. The comparison of the effects of high-dose and low-dose ATD is useful for other studies aiming to investigate relationships among 5-HT, mood and cognition.

\section{Acknowledgements}

This research was supported by grants from the Dutch Organization of Sciences - Medical Sciences (NWO-MW) and the 'Stichting tot Steun VCVGZ'. The authors thank Milad Kavehzadeh and SannekeVan Vliet for assistance in data collection, and the dieticians and staff of the laboratory and pharmacy of Parnassia and the laboratory of psychiatry of Erasmus Medical Center for their technical assistance.

\section{References}

Austin M P, Mitchell P, Goodwin G M (2001) Cognitive deficits in depression: possible implications for functional neuropathology. $\mathrm{Br} \mathrm{J}$ Psychiatry 178: 200-206

Booij L, Van der Does W, Benkelfat C, Bremner J D, Cowen P J, Fava M, Gillin C, Leyton M, Moore P, Smith K A, Van der Kloot WA (2002) Predictors of mood response to acute tryptophan depletion. A reanalysis. Neuropsychopharmacology 27: 852-861

Booij L, Van der Does A J W, Riedel W J (2003) Monoamine depletion in psychiatric and healthy populations: review. Mol Psychiatry 8: 951-973

Bremner J D, Innis R B, Salomon R M, Staib L, Ng C K, Miller H L, Bronen R A, Krystal J H, Duncan J, Rich D, Price L H, Malison R, Dey H, Soufer R, Charney D S (1997) Positron emission tomography measurement of cerebral metabolic correlates of tryptophan depletioninduced depressive relapse. Arch Gen Psychiatry 54: 364-374

Burt D B, Zembar M J, Niederehe G (1995) Depression and memory impairment: a meta-analysis of the association, its pattern, and specificity. Psychol Bull 117: 285-305

Carpenter L L, Anderson G M, Pelton G H, Gudin J A, Kirwin P D, Price L H, Heninger G R, McDougle C J (1998) Tryptophan depletion during continuous CSF sampling in healthy human subjects. Neuropsychopharmacology 19: 26-35

Deijen J B, Orlebeke J F (1994) Effect of tyrosine on cognitive function and blood-pressure under stress. Brain Res Bull 33: 319-323

Delgado P L, Charney D S, Price L H, Aghajanian G K, Landis H, Heninger G R (1990) Serotonin function and the mechanism of antidepressant action. Reversal of antidepressant-induced remission by rapid depletion of plasma tryptophan. Arch Gen Psychiatry 47: 411-418

Delgado P L, Miller H L, Salomon R M, Licinio J, Krystal J H, Moreno F A, Heninger G R, Charney D S (1999) Tryptophan-depletion challenge in depressed patients treated with desipramine or fluoxetine: implications for the role of serotonin in the mechanism of antidepressant action. Biol Psychiatry 46: 212-220

Fekkes D, van Dalen A, Edelman M, Voskuilen A (1995) Validation of the determination of amino acids in plasma by high-performance liquid chromatography using automated pre-column derivatization with o-phthaldialdehyde. J Chromatogr B Biomed Appl 669: 177-186

Fekkes D, Timmerman L, Pepplinkhuizen (1997) Effects of clomipramine on plasma amino acids and serotonergic parameters in panic disorder and depression. European Neuropsychopharmacology 7: 235-239

First M B, Spitzer R L, Gibbon M, Williams J B W (1995) Structured Clinical Interview for DSM-IV Axis I Disorders, Patient edn (SCIDI/P). Biometrics Research Department, NYSPI, New York

Frank E, Prien R F, Jarrett R B, Keller M B, Kupfer D J, Lavori P W, Rush A J, Weissman M M (1991) Conceptualization and rationale for consensus definitions of terms in major depressive disorder - remission, recovery, relapse, and recurrence. Arch Gen Psychiatry 48: 851-855

Gallagher P, Massey A E, Young A H, McAllister-Williams R H (2003) Effects of acute tryptophan depletion on executive function in healthy male volunteers. BMC Psychiatry 3: 2-20

Gotlib I H, McCann C D (1984) Construct accessibility and depression an examination for cognitive and affective factors. J Pers Soc Psychol 47: $427-439$ 
Hamilton M (1960) A rating scale for depression. J Neurol Neurosurg Psychiatry 23: 56-62

Harmer C J, Bhagwagar Z, Perrett D I, Vollm B A, Cowen P J, Goodwin G M (2003a) Acute SSRI administration affects the processing of social cues in healthy volunteers. Neuropsychopharmacology 28: 148-152

Harmer C J, Rogers R D, Tunbridge E, Cowen P J, Goodwin G M (2003b) Tryptophan depletion decreases the recognition of fear in female volunteers. Psychopharmacology (Berl) 167: 411-417

Harrison B J, Olver J S, Norman T R, Burrows G D, Wesnes K A, Nathan P J (2004) Selective effects of acute serotonin and catecholamine depletion on memory in healthy women. J of Psychopharmacol 18: 32-40

Klaassen T, Riedel W J, Deutz N E, van Someren A, Van Praag H M (1999) Specificity of the tryptophan depletion method. Psychopharmacology 141: 279-286

Krahn L E, Lu PY, Klee G, Delgado P R, Lin S C, Zimmermann R C (1996) Examining serotonin function: a modified technique for rapid tryptophan depletion. Neuropsychopharmacology 15: 325-328

Maes M, Meltzer H Y (1995) The serotonin hypothesis of major depression. In Bloom F E, Kupfer D J (eds), Psychopharmacology: The Fourth Generation of Progress. Raven Press, New York

Markus C R, Panhuysen G, Tuiten A, Koppeshaar H, Fekkes D, Peters M L (1998) Does carbohydrate-rich, protein-poor food prevent a deterioration of mood and cognitive performance of stress-prone subjects when subjected to a stressful task? Appetite 31: 49-65

Markus C R, Olivier B, de Haan E H F (2002) Whey protein rich in alphalactalbumin increases the ratio of plasma tryptophan to the sum of the other large neutral amino acids and improves cognitive performance in stress-vulnerable subjects. Am J Clin Nutr 75: 1051-1056

Montgomery S A, Asberg M (1979) A new depression scale designed to be sensitive to change. Br J Psychiatry 134: 382-389

Murphy F C, Smith K A, Cowen P J, Robbins T W, Sahakian B J (2002) The effects of tryptophan depletion on cognitive and affective processing in healthy volunteers. Psychopharmacology (Berl) 163: 42-53

Neale J M, Liebert R M (1986) Science and Behavior: An Introduction to Methods and Research, 3rd edn. Prentice Hall, Englewood Cliffs, NJ

Nehlig A (1999) Are we dependent upon coffee and caffeine? A review on human and animal data. Neurosci Biobehav Rev 23: 563-576

O'Reardon J P, Chopra M P, Bergan A, Gallop R, De Rubeis R J, Crits-Christoph P (2004) Response to tryptophan depletion in major depression treated with either cognitive therapy or selective serotonin reuptake inhibitor antidepressants. Biol Psychiatry 55: 957-959

Owen A M, Sahakian B J, Semple J, Polkey C E, Robbins T W (1995) Visuo-spatial short-term recognition memory and learning after temporal lobe excisions, frontal lobe excisions or amygdalo-hippocampectomy in man. Neuropsychologia 33: 1-24

Park S B, Coull J T, McShane R H, Young A H, Sahakian B J, Robbins T W, Cowen P J (1994) Tryptophan depletion in normal volunteers produces selective impairments in learning and memory. Neuropharmacology 33: 575-58

Riedel W J, Klaassen T, Deutz N E, van Someren A, Van Praag H M (1999) Tryptophan depletion in normal volunteers produces selective impairment in memory consolidation. Psychopharmacology (Berl) 141: 362-369

Rubinsztein J S, Rogers R D, Riedel W J, Mehta M A, Robbins T W, Sahakian B J (2001) Acute dietary tryptophan depletion impairs maintenance of 'affective set' and delayed visual recognition in healthy volunteers. Psychopharmacology (Berl) 154: 319-326

Schaefer A, Collette F, Philippot P, Van der Linden M, Laureys S, Delfiore G, Degueldre C, Maquet P, Luxen A, Salmon E (2003) Neural correlates of 'hot' and 'cold' emotional processing: a multilevel approach to the functional anatomy of emotion. Neuroimage 18: 938-949

Schmitt J A, Jorissen B L, Sobczak S, van Boxtel M P, Hogervorst E, Deutz N E, Riedel W J (2000) Tryptophan depletion impairs memory consolidation but improves focussed attention in healthy young volunteers. J Psychopharmacol 14: 21-29

Schruers K, Klaassen T, Pols H, Overbeek T, Deutz NE, Griez E (2000) Effects of tryptophan depletion on carbon dioxide provoked panic in panic disorder patients. Psychiatry Res 93: 179-187

Segal Z V, Gemar M, Truchon C, Guirguis M, Horowitz L M (1995) A priming methodology for studying self-representation in major depressive disorder. J Abnorm Psychol 104: 205-213

Silverman K, Evans S M, Strain E C, Griffiths R R (1992) Withdrawal syndrome after the double-blind cessation of caffeine consumption. New Engl J Med 327: 1109-1114

Smith A (2002) Effects of caffeine on human behavior. Food Chem Toxicol 40: $1243-1255$

Smith K A, Fairburn C G, Cowen P J (1997) Relapse of depression after rapid depletion of tryptophan. Lancet 349: 915-919

Smith K A, Morris J S, Friston K J, Cowen P J, Dolan R J (1999) Brain mechanisms associated with depressive relapse and associated cognitive impairment following acute tryptophan depletion. Br J Psychiatry 174: 525-529

Sobczak S, Riedel W J, Booij L, Aan Het Rot M, Deutz N E, Honig A (2002) Cognition following acute tryptophan depletion: difference between first-degree relatives of bipolar disorder patients and matched healthy control volunteers. Psychol Med 32: 503-515

Spillmann M K, Van der Does A J, Rankin M A, Vuolo R D, Alpert J E, Nierenberg A A, Rosenbaum J F, Hayden D, Schoenfeld D, Fava M (2001) Tryptophan depletion in SSRI-recovered depressed outpatients. Psychopharmacology (Berl) 155: 123-127

Van der Does A J W (2001a) The effects of tryptophan depletion on mood and psychiatric symptoms. J Affect Disord 64: 107-119

Van der Does A J W (2001b) The mood-lowering effect of tryptophan depletion: possible explanation for discrepant findings. Arch Gen Psychiatry 58: 200-202

Weltzin T E, Fernstrom J D, McConaha C, Kaye W H (1994) Acute tryptophan depletion in bulimia: effects on large neutral amino acids. Biol Psychiatry 35: 388-397

Young S N, Smith S E, Pihl R O, Ervin F R (1985) Tryptophan depletion causes a rapid lowering of mood in normal males. Psychopharmacology (Berl) 87: 173-177 